\title{
Memoria colectiva y construcción de territorio: auge y despojo de una cultura industrial. Los casos de la fábrica textil Bellavista-Tomé y la carbonífera Schwager en Coronel (1970-2007)
}

\author{
Collective memory and construction of territory: boom and dispossession of \\ an industrial culture. The cases of the textile factory Bellavista-Tomé and the \\ coal company Schwager in Coronel (1970-2007)
}

\author{
Alejandra Brito Peña*
}

\begin{abstract}
Resumen: Este trabajo rescata la experiencia de auge y despojo cultural de trabajadores/as del carbón en Coronel y textiles en Tomé, a partir de sus propias voces. El objetivo es comprender las relaciones sociales y laborales, de estos espacios productivos, durante el período de la Unidad Popular y la Dictadura. A la vez, consideramos los procesos de reestructuración económica y los efectos provocados por la crisis que genera el cierre de las industrias y el fracaso del proceso de reconversión. Finalmente, incluimos las respuestas actuales que se producen a través de la activación patrimonial.
\end{abstract}

Palabras clave: industrialización, desindustrialización, memoria, cultura industrial.

Abstract: This paper recovers the experience of coal workers from Coronel and Textiles workers from Tomé during cultural peak and dispossession, from their own opinions. The objective of the research is to understand the social and labour relations of these productive spaces during the Unidad Popular and Dictadura' period. At the same time, procesess of economical restructuring and the effects generated by the crisis which provokes the closure and the failure in the reprove process. Finally, current answers produced through the heritage activation have been included. activation.

Keywords: industrialization, deindustrialization, memory, industrial culture

Recibido: 15 diciembre 2017

Aceptado: 6 febrero 2018

\footnotetext{
* Chilena, Doctora en Estudios Americanos, mención Historia. Docente e Investigadora de la Universidad de Concepción. Proyectos CONICYT: PIA Soc 1403 (2015-2018) y FONDECYT 1171100 (2017-2020), abrito@udec.cl
} 


\section{Introducción}

Hasta 1973 el país y la región habían consolidado un proceso industrializador, que ya contaba con más de 100 años de evolución. Este proceso se inició en el último tercio del siglo XIX y se fortaleció por la acción del Estado a mediados del siglo XX. Las actividades productivas generaron una concentración de mano de obra de carácter obrera, asentada en el territorio, lo que permitió el desarrollo de una cultura industrial que incluyó una identidad territorial que marcó varias generaciones. En el estudio que presentamos, se trabajó con dos zonas industriales: la de la industria textil Bellavista-Tomé, creada en 1865 y que funcionó hasta 2007 (reabre el 2010 pero con un número muy reducido de trabajadores); y la de la industria carbonífera en Puchoco-Schwager que funcionó ininterrumpidamente desde 1892 hasta 1994.

La reconstrucción histórica del período en estas dos industrias, se realizó a partir de los relatos individuales y colectivos de extrabajadores/as y/o sus esposas; además, se consideraron los discursos públicos extraídos del diario El Sur de Concepción. La recuperación de la memoria de extrabajadores/as, transitó desde las memorias sueltas a las memorias emblemáticas, organizando las memorias concretas articuladas en un sentido mayor, que incluyó la selección y los olvidos. Así, "la historia de la memoria y el olvido es un proceso de deseo y de lucha para construir las memorias emblemáticas, culturalmente y políticamente influyentes y hasta hegemónicas"1. Lo que se buscó fue configurar puentes entre la experiencia individual y colectiva a partir de ciertos hechos o coyunturas que tensionaron las experiencias vividas. El cierre de las industrias y la crisis que generó, activó la memoria colectiva, que revalorizó el trabajo industrial. De esta manera la memoria colectiva se nutrió de los marcos sociales del momento en que se activó, reconstruyendo el pasado, mirándolo desde el presente ${ }^{2}$. Así, por ejemplo, a pesar de la crudeza y el peligro de trabajar en las minas del carbón, internándose por laberintos debajo del mar, el "meterse al hoyo" -como lo llaman los trabajadores - terminó siendo la añoranza de un trabajo seguro, frente a la incertidumbre que dejó el cierre de la faena productiva que construyó un territorio social y material.

El cierre de las industrias se dio en el contexto de la instauración del modelo económico neoliberal, a partir de la dictadura cívico-militar, que se instaló en el país después del golpe militar de 1973. Lo que se vivió fue un proceso de despojo neoliberal que transformó la economía, al cerrar el ciclo productivo desarrollista, que estimuló la industrialización. Este nuevo modelo de desarrollo se basó - como plantea Harvey - en la acumulación por desposesión, que terminó con los mecanismos de protección que el liberalismo había aceptado luego de las crisis económicas, y que fue consolidado en el período desarrollista. Así, el “...abandono por parte del Estado de las medidas de protección social cubiertas por el sistema de bienestar y los cambios inducidos por la

\footnotetext{
${ }^{1}$ Steve Stern, "De la memoria suelta a la memoria emblemática: hacia un recordar y el olvidar como proceso histórico (Chile 1973 - 1998)". En M. Garcés y otros Memoria para un nuevo siglo. Chile, miradas a la segunda mitad del siglo XX. LOM Ediciones, Santiago de Chile, 2000, pp. 11-33, p. 13

${ }^{2}$ Maurice Halbwachs: La memoria colectiva, Prensas Universitarias de Zaragoza, Zaragoza, 2004.
} 
tecnología en la estructura del empleo..., culminan el proceso de erigir el dominio del capital sobre la fuerza de trabajo en el mercado"3. Esta acumulación por desposesión se basó, en cuatro aspectos: 1) La Privatización y Mercantilización, que rentabilizó áreas como los servicios públicos, la previsión social, la educación pública, a la vez que mercantilizó la vida incluyendo la creación cultural, generando así una política de desposesión. 2) La Financiarización, que permitió al sistema financiero transformarse en un "centro de actividad redistributiva, a través de la especulación, la depredación, el fraude y el robo". 3) La Gestión y manipulación de la crisis, a nivel de escala mundial que ha derivado en "la redistribución deliberada de la riqueza desde los países pobres hacia los ricos". 4) Las Redistribuciones estatales, que derivaron en los recortes del gasto público, haciendo que las privatizaciones generaran efectos negativos en el largo plazo en las clases más bajas ${ }^{4}$.

Este despojo, va más allá del término de un proceso productivo y se vincula más con la pérdida de una cultura industrial, que los ha dejado - según sus propias voces - con "las manos cortadas". A lo cual se suma el desmantelamiento de los vestigios materiales del pasado industrial, lo que se lee como un intento de borrar su memoria. Esto ha llevado, en la actualidad, a la defensa y protección patrimonial, en tanto la conservación y activación actúan reactualizando la memoria colectiva.

\section{Auge y caída del desarrollo industrial en Chile}

Desde mediados del siglo XIX hasta las primeras décadas del siglo XX se produjo en el país un proceso de industrialización temprana asociada al proceso de modernización capitalista, que abrió los mercados nacionales a partir de la independencia. La producción industrial se vio favorecida en el último tercio del siglo XIX por el auge salitrero y los conflictos bélicos. Las industrias creadas durante el período de la industrialización temprana, se vieron favorecidas con el nuevo ciclo industrial propiciado por el Estado a mediados del siglo XX. El período que va entre 1940 y 1973, presentó un mayor auge industrial, liderado por el Estado y su nueva propuesta de desarrollo. El Estado fue adquiriendo diversas funciones, transformándose en el impulsor de un crecimiento gradual pero continuo, y aplicando numerosas reformas sociales, ya sea como Estado-promotor (dando crédito para la inversión industrial privada); Estado-empresario (creación de empresas estatales); Estado-programador, que definía las políticas de desarrollo y especificaba adonde debía ir la inversión futura, fuese pública o privada ${ }^{5}$.

Con la llegada a la presidencia del candidato del Frente Popular, Pedro Aguirre Cerda, en 1938, se planteó un modelo de desarrollo "hacia adentro", donde el Estado lideraría las transformaciones estructurales. Esto dio paso a la política de Industrialización

\footnotetext{
${ }^{3}$ David Harvey, Breve historia del neoliberalismo, en https://teoriaeconomicatercersemestreri.files.wordpress.com/2012/09/breve-historia-del-neoliberalismo-dedavid-harvey1.pdf, p. 175

${ }^{4}$ Ibidem, pp. 167-171

${ }^{5}$ Patricio Meller, Un siglo de economía política chilena (1890-1990). Santiago: Editorial Andrés Bello, 1996.
} 
Sustitutiva de Importaciones (ISI). Lo primero fue la creación en 1939 de la Corporación de Fomento de la Producción (CORFO), cuyo objetivo era fomentar la producción y crear desde el Estado la infraestructura básica para diversificar la producción y ampliar los mercados, incluyendo el mercado interno. Esto llevó a la creación de empresas estatales de industrias básicas en la energía, la siderurgia y otros rubros. En 1944 se crea la Empresa Nacional de Electricidad (ENDESA), en 1946 la Compañía de Acero del Pacífico (CAP), en 1950 la Empresa Nacional de Petróleo (ENAP) y en 1952 la Industria Azucarera Nacional. Junto a estas industrias se elaboraron planes estratégicos de desarrollo. Por un lado, un plan de electrificación del país con la construcción de varias centrales hidroeléctricas; y por otro, las refinerías de petróleo de Concón y Concepción y la Siderúrgica de Huachipato ${ }^{6}$.

La incorporación de los sectores marginados al mercado requería una nueva política de relaciones laborales, que efectivamente les permitiera a los trabajadores tener el poder adquisitivo que los transformara en consumidores de la producción nacional. En este sentido, la sindicalización cumplió un papel central al presionar por mejoras salariales, que permitían el acceso a bienes y servicios que el mercado les ofrecía. El Estado oligárquico y explícitamente excluyente, dio paso a un Estado más incluyente, que promovía un nuevo pacto social - el "Estado de Compromiso" - posibilitando la creación de nuevas formas de relación entre el Estado y los distintos actores sociales ${ }^{7}$. Este nuevo marco queda legitimado con la promulgación del Código Laboral en 1931. Este proceso alcanza su máximo desarrollo durante el período de la Unidad Popular. El gobierno de Salvador Allende llevó un plan de estatización de industrias, las que pasaron al área social. Si bien el programa planteaba que se aplicaría a áreas estratégicas, en la práctica la utilización del Decreto 1262 de 1953, le otorgó el mecanismo legal para ampliar el número de industrias estatizadas. En su art. $5^{\circ}$ el decreto establecía que "Todo establecimiento industrial o comercial, y toda explotación agrícola que se mantenga en receso, podrá ser expropiada por el Presidente de la República"8.

El ciclo de crecimiento industrial nacional y regional se vio fuertemente golpeado durante el período de la dictadura cívico-militar. A partir de un golpe de estado de 1973, se desarrolló un plan de reformas neoliberales que comenzaron paulatinamente a desmantelar el proyecto industrializador y desarrollista, iniciándose un proceso de desindustrialización. El postulado principal del neoliberalismo fue que el mercado debía estar libre de toda intervención estatal, como la manera más adecuada de organizar la sociedad y resolver los

\footnotetext{
${ }^{6}$ Mayor información sobre el tema en Enrique Aliste, Miguel Almuna, Alonso Contreras y Valeria Sandoval. "Industrialización, Desarrollo y Ciudad: Transformaciones Socio-demográficas y Espaciales en la Geografía Social del Gran Concepción (1950-2010)", Revista Invi, Vol. 27 N 75, agosto 2012, pp. 21-71; Compañía de Acero del Pacífico. Desarrollo y Expansión de Huachipato. Preparado por el Servicio de Divulgación Industrial de la Compañía de Acero del Pacífico S. A. Litografía Stanley, Santiago, 1962.

${ }^{7}$ Enrique Fernández, Estado y sociedad en Chile 1891-1931: el estado excluyente, la lógica estatal oligárquica y la formación de la sociedad, Santiago, LOM, 2003.

${ }^{8}$ Decreto 1262 de 18 de noviembre de 1953, www.leychile.cl
} 
dilemas sociales. Para el caso de Chile, algunos autores ${ }^{9}$ sostienen que esta doctrina se remonta a la década de 1950, cuando el gobierno de Carlos Ibañez del Campo, promueve un plan de restauración económica, denominada misión Klein-Sacks (1955-1958). Las principales medidas propuestas por este programa fueron: 1) reducir el déficit fiscal; 2) aumentar las importaciones y diversificar las exportaciones; 3) fomentar la inserción de capitales extranjeros y; 4) eliminar el control estatal de los precios. A pesar de que este programa no tuvo un apoyo mayoritario, el que la liberalización de la economía haya sido fomentada por el gobierno, además de la fuerte campaña comunicacional a favor realizada por medios como El Mercurio, permiten sostener que lo que en el futuro se denominará como neoliberalismo (el nombre común de la época era monetarismo), ya era aceptado por ciertos sectores de la elite político-económica chilena.

Si bien no existieron antecedentes similares a la misión Klein-Sacks en las décadas posteriores, fue en aquellos mismos años cuando comienza la historia oficial del neoliberalismo chileno. En 1955, se lleva a cabo un acuerdo entre la Pontificia Universidad Católica de Chile y la Agencia Americana para el Desarrollo Internacional con el propósito de incentivar el intercambio académico con la Universidad de Chicago. De este acuerdo surgen gran parte de las figuras claves de las reformas político-económicas de la dictadura militar de Augusto Pinochet. Entre los participantes de este plan de intercambio estuvieron: Pablo Barahona, Álvaro Bardón, Emilio Sanfuentes, Rolf Lüders, Sergio de la Cuadra, Manuel Cruzat, Ernesto Silva, Cristián Larroulet, Felipe Lamarca, Ernesto Fontaine, Miguel Kast y Joaquín Lavín. Tanto en la Página Económica de El Mercurio como en la revista Qué Pasa, los mayores medios promotores del pensamiento de la escuela de Chicago, los escritos de estos economistas fueron frecuentes ${ }^{10}$.

Las reformas llevadas a cabo por los herederos de la Escuela de Chicago en Chile pueden dividirse en dos periodos ${ }^{11}$. Primero, en 1979, se implementan las denominadas Siete Modernizaciones, basadas en la privatización de los sectores de la salud, la educación y la previsión; la regionalización, tanto del sistema judicial como de la burocracia gubernamental y la desregulación del mercado laboral. Luego, tras la crisis de 1983, estas medidas se radicalizan. Hernán Büchi, Ministro de Hacienda de la época, comanda la privatización de cerca de 400 empresas con participación total o parcial del Estado, entre estas, ENTEL, CHILECTRA, IANSA y CAP, siendo capitales españoles los mayores beneficiados con estas ventas. En 1973, la CORFO controlaba la propiedad de 300 empresas. En 1980 este número alcanzaba a 24 y la mitad de ellas estaban en proceso de licitación, lo que se mantuvo aun en medio de la crisis económica de $1982^{12}$.

\footnotetext{
${ }^{9}$ Francisco Campo, Antecedentes del neoliberalismo en Chile (1955-1975), Santiago, Universidad de Chile, 2013.

${ }^{10}$ Sofía Correa, María Consuelo Figueroa, Alfredo Jocelyn-Holt, Claudio Rolle, Manuel Vicuña, Historia de Chile en el siglo XX: balance paradojal, Santiago, Editorial Sudamericana, 2001.

${ }^{11}$ Ricardo Ffrench-Davis, Chile entre el neoliberalismo y el crecimiento con equidad: cuarenta años de políticas económicas y sus lecciones para el futuro, Santiago, J.C. Sáez, 2003; Pilar Vergara, Auge y caída del neoliberalismo en Chile, Santiago, FLACSO, 1985.

${ }^{12}$ Ffrench-Davis, op. cit.
} 
La desindustrialización fue entonces un plan consciente, a pesar de no existir una declaración explícita de desindustrializar el país. Sin embargo, “...era evidente para cualquier observador que la implantación de una política económica tan ortodoxamente laissez-fairiana necesariamente conllevaba un fuerte deterioro de la importancia del sector industrial. Como contrapartida casi inevitable, producía una reespecialización primaria exportadora"13. Bajo esta política la mayoría de las industrias de bienes de consumo del país comienzan a desaparecer, siendo el rubro textil uno de los más golpeados. Frente a la apertura del mercado a telas importadas de países como China, la industria nacional deja de ser competitiva en el mercado interno. A ello se suma el término de la estatización en la mayoría de las empresas que pasaron al área social bajo el gobierno de la Unidad Popular y que habían sido co-administradas por los interventores estatales y los trabajadores. Lo que se planteó fue una refundación nacional, para ello el sector privado alcanzó un sitial protagónico "de los procesos de acumulación y crecimiento, reduciendo — tanto como ello fuese posible - la incidencia de los factores que afectaban negativamente la valorización de sus capitales"14. A lo cual se agrega la transformación del Estado, al reducir su tamaño y al "anular o revertir la mayoría de las conquistas sociales de los trabajadores, de manera de establecer nuevas relaciones capital/trabajo, más favorables al capital y a impulsar la profundización de la inserción de Chile en ese mundo en acelerada globalización"15.

Uno de los aspectos que modificó radicalmente la relación capital-trabajo fue la puesta en marcha del llamado Plan Laboral, liderado por José Piñera, como ministro del trabajo. Piñera fue llamado por el gobierno militar en 1979 para hacerse cargo de la modernización de las relaciones laborales, para que fuesen acordes al nuevo modelo económico. En un contexto social de alta represión, que golpeó muy fuerte el mundo sindical, el Plan Laboral se impuso. Este se componía de "un conjunto de decretos-leyes, su objetivo fue implementar la lógica neoliberal tanto al interior de las organizaciones de los trabajadores, como en las relaciones entre el capital y el trabajo"16. Fortaleció el surgimiento de una base sindical despolitizada, que fue más funcional a los intereses del nuevo modelo laboral y que aseguró menores índices de conflictividad; un sindicato de carácter más empresarial, más partidario de la negociación que del conflicto ${ }^{17}$. La puesta en práctica de las nuevas formas de negociación establecidas por el Plan Laboral, atomizó los sindicatos, al permitir la libre asociación en las empresas, por lo que podían existir múltiples sindicatos y negociar de manera separada, al igual que lo podían hacer los propios trabajadores de manera individual. Por otro lado, se posibilitaba la huelga, pero bajo ciertas

\footnotetext{
${ }^{13}$ Carlos Vignolo, "De la desindustrialización a una nueva industrialización en un Chile democrático", CED, Centro de Estudios del Desarrollo, Santiago, Chile, 1986, pp. 204-205.

${ }^{14}$ Carlos De Mattos, "Modernización neocapitalista, reestructuración productiva y territorial en Chile, 1973 90”, Revista Eure, Vol. XVIII, N 54, 1992, pp. 15-30, p. 18.

15 Idem

${ }^{16}$ Rolando Álvarez, "El Plan Laboral y la negociación colectiva: ¿Origen de un nuevo sindicalismo en Chile? 1979-1985", Boletín del Instituto de Historia Argentina y Americana "Dr. Emilio Ravignani", Tercera serie, núm. 35/36, segundo semestre 2011 / primer semestre 2012, pp. 92 - 115, p. 92.

17 Jorge Ayala. Historia del movimiento sindical de Huachipato 1970-2013. Procesos de articulación y acción política. Editorial Escaparate, Concepción-Chile, 2016.
} 
condiciones, como el hecho de que esta no podía durar más de 60 días (si se excedía ese plazo eran las propuestas patronales las que se aprobaban) y se autorizaba también la contratación de trabajadores de reemplazo. Si más del 50\% de la fuerza laboral iba a la huelga, el empleador tenía derecho a declarar el "lock out" o cierre forzoso. En la práctica, esta nueva ley laboral no protegía al trabajador al consagrar - además de lo ya señalado - la posibilidad de despedirlo solo argumentando "necesidades de la empresa"18. Lo que se logró fue institucionalizar un marco de negociación restringido. Así "parte del descontento social se canalizó bajo las reglas neoliberales, las que se legitimaron por la vía de los hechos"19. A partir de la década de 1990, luego del retorno a la democracia, se realizaron algunas reformas al sistema, pero la esencia de este modelo no se transformó ${ }^{20}$.

\section{Auge, caída y despojo de una experiencia industrial: la industria del carbón en Schwager y la industria textil de Bellavista Tomé}

En esta sección analizaremos la instalación de las industrias desde sus inicios y conoceremos la percepción que tienen los habitantes de los territorios, en relación al cierre de las faenas productivas, lo que implicó además el cierre de la forma de habitar que conocieron y vivenciaron varias generaciones. Metodológicamente, para el rescate de las voces de los habitantes actuales de los barrios industriales estudiados, se realizaron talleres entre el 2014 y el 2016 utilizando la estrategia de los mapeos colectivos, que buscan territorializar la memoria. Se realizaron 4 talleres, dos por cada territorio, separados por sexo. Además, se realizaron historias de vidas de ex trabajadores/as y esposas de trabajadores para el caso del carbón. Finalmente, en el caso de Tomé se complementó con entrevistas en profundad.

El análisis se centrará en tres aspectos: el primero, una breve reseña histórica de las dos industrias trabajadas. El segundo, los significados que tuvo para trabajadores/as y sus familias el "auge de la clase trabajadora" con el gobierno de la Unidad Popular, considerando que ambas empresas fueron estatizadas en dicho período. Finalmente, el impacto del cierre del ciclo productivo característico de los territorios, incorporando el sentimiento de despojo que significó el cierre de las faenas productivas. Además, la ineficacia de los planes de reconversión que se generaron específicamente en la zona carbonífera.

\footnotetext{
${ }^{18}$ Aníbal Navarrete, Gina Inostroza, Tres tesis sobre Tomé: Tres enfoques sobre la historia textil de Tomé. Editorial: Al Aire Libro, 2009, p. 40

19 Álvarez, op. cit., p. 98

${ }^{20}$ Gabriel Salazar, Julio Pinto, Historia Contemporánea de Chile. La economía: mercado, empresarios y trabajadores, Santiago, LOM, 2002; Manuel Antonio Garretón, Neoliberalismo corregido y progresismo limitado: los gobiernos de la concertación en Chile, Santiago, CLACSO, 2013.
} 


\section{1- $\quad$ El desarrollo de las industrias del carbón y textil hasta 1970}

La Compañía Carbonífera y de Fundición Schwager fue fundada en el año 1892 por el empresario de origen alemán Federico Schwager, aunque la explotación del carbón en la zona había comenzado 40 años antes. El desarrollo de la minería del carbón en el sector Puchoco supuso una completa transformación del territorio, no sólo a través de la instalación de equipamientos asociados a la actividad productiva, sino también mediante la construcción de edificaciones destinadas a satisfacer las necesidades de la mano de obra minera. En una primera etapa, la evolución urbana del barrio Puchoco en Schwager estuvo impulsada por el factor productivo, modificándose el paisaje producto de las instalaciones realizadas para optimizar la extracción el mineral. ${ }^{21}$ Cabe mencionar que los primeros asentamientos mineros surgieron de forma espontánea en 1872, situándose a cada lado de la línea férrea que se extiende hacia el sur del Biobío. En el año 1877, se construyeron los primeros pabellones ubicados alrededor de la mina Puchoco. La época de esplendor de Puchoco-Schwager estuvo vinculada a la intensa construcción de viviendas y edificios de equipamiento promovidos por la compañía carbonífera, con el fin de mejorar la calidad de vida de sus trabajadores. Así, podemos decir que entre 1920 y 1950, Schwager se constituye, en un claro modelo de ciudad industrial ${ }^{22}$.

La Fábrica de Paños Bellavista Tomé, fue fundada por el empresario norteamericano Guillermo Gibson Délano, en 1865. Gracias a las habilidades administrativas del empresario y sus acertadas inversiones, más la existencia de una mano de obra barata, la Fábrica de Paños Bellavista comenzó su crecimiento. Ya durante los primeros años de la década de 1870 contaba con más de un centenar de trabajadores y trabajadoras, provenientes principalmente de los alrededores de Tomé, además de los técnicos norteamericanos. Parte importante de la mano de obra de la fábrica la constituyeron mujeres.

Tras la muerte de Guillermo Gibson Délano, la fábrica fue vendida al técnico alemán Augusto Kaiser (1879). Bajo su administración la fábrica recibió un importante impulso, por la compra de telas para uniformes del ejército chileno que participaba en la Guerra del Pacífico, por parte del gobierno de Aníbal Pinto ${ }^{23}$. Entre 1890 y 1912 la fábrica pasó por varios dueños ${ }^{24}$. En el año 1912, Carlos Werner, quedó como único dueño de la empresa. A partir de entonces, la fábrica adquirió una nueva fisonomía productiva, caracterizada por el uso de modernas maquinarias europeas y la distribución de las faenas en departamentos especializados. Además, gracias a la llegada del ferrocarril en el año 1916, la fábrica pudo obtener, en menor tiempo, las materias primas que necesitaba, entre ellas, la lana y el carbón para el funcionamiento de las calderas.

${ }^{21}$ Leonel Pérez, "El barrio Puchoco en Schwager. Cuando la industria construye el paisaje cultural", en Urbano, Vol. $\mathrm{N}^{\circ} 11, \mathrm{~N}^{\circ} 16,2008$, pp. 47-58, p. 51.

${ }^{22}$ Ibidem, p. 51.

${ }^{23}$ Ibidem, p. 16.

${ }^{24}$ Armando Cartes, "Fábrica de Paños Bellavista, Espacio y Tiempo (1865-1970). En Armando Cartes, Rodrigo Luppi, Luis López, Bellavista Oveja Tomé. Una fábrica en el tiempo, Ediciones Universidad San Sebastián, Universidad San Sebastián, Concepción, Chile, 2012, pp. 23-48.. 
Carlos Werner construyó en Bellavista un poblado industrial, que incluyó viviendas para los trabajadores y equipamiento urbano. Este empresario se preocupó por el bienestar de sus trabajadores, poniendo especial atención en sus condiciones laborales y de habitabilidad. Así, bajo una lógica empresarial paternalista, desarrolló un conjunto de obras sociales. Por esta razón, la "administración alemana", iniciada por Werner, ha sido reconocida como uno de los periodos de mayor esplendor de la fábrica.

En ambas empresas existieron prácticas de paternalismo industrial, que buscaron transformar al trabajador $\mathrm{y}$ sus familias en sujetos disciplinados, responsables y productivos. Se utilizaron mecanismos diversos, dirigidos en su mayoría al núcleo familiar completo. De allí que el modelo se sustentara en las ideas de "Atraer y fijar, disciplinar: he ahí sus dos líneas preferentes de ataque. En su íntima articulación ambas definen el espacio de la más formidable operación de modelado poblacional y social que conocen los tiempos modernos: la habituación del trabajador" ${ }^{25}$. El proceso tuvo un carácter fuertemente pragmático. El objetivo era darles a los trabajadores/as y sus familias mejores condiciones de vida, pero en un contexto de permanente vigilancia ${ }^{26}$. Esta intervención de los modos de vivir era una forma de asegurar la reproducción de la mano de obra, a la vez que alejaba a los obreros de los peligros de las ideas socialistas y anarquistas que se difundían rápidamente en los centros de trabajadores, tanto en Europa como más tarde en Latinoamérica, aunque en la práctica no se logró. Para corregir "el comportamiento rebelde de los trabajadores, las empresas empezaron a regular también los espacios sociales en los que estos reproducían su fuerza de trabajo, como la vivienda, los lugares de esparcimiento y así nació la llamada fábrica-ciudad"27.

Una de las estrategias más efectivas para lograr el asentamiento permanente y diseñar mejores políticas de control hacia la población, fue la construcción de viviendas. En ambas empresas se generó una política habitacional. Dos elementos caracterizaron dicha política: en primer lugar, la construcción de viviendas las realizaba la empresa y por lo tanto eran de su propiedad, las que eran entregadas a las familias. Estas debían mantenerlas en buenas condiciones y por sobre todo mantener un comportamiento adecuado para seguir usufructuando de ellas. El segundo aspecto fue el diseño de un tramado urbano altamente segregado, generando habitaciones para obreros, separadas de las de empleados y técnicos, lo cual implicaba, además, la instalación de servicios diferenciados y en los cuales existían barreras físicas de separación.

En Puchoco-Schwager se construyeron, como en toda la zona del carbón, pabellones residenciales para las familias y, en el sector de Maule, residencias para los empleados, conformando dos zonas claramente diferenciadas y estratificadas. Los edificios de servicio comunitario constituyeron otra zona diferenciada en el sector, los que estaban ubicados

\footnotetext{
25 José Sierra Álvarez, El obrero soñado. Ensayo sobre el paternalismo industrial (Asturias, 1860-1917), Siglo XXI, Madrid, España, 1990, p.14.

${ }^{26}$ Macario Alemany García, El concepto y la justificación del paternalismo. Tesis para optar al grado de Doctor en Derecho por la Facultad de Derecho de la Universidad de Alicante, 2005. http://www.archivochile.com/tesis/13_otros/13otros0013.pdf.

${ }^{27}$ Griselda Lemiez, Relaciones laborales paternalistas en la industria del cemento. El caso de Avellaneda, Olavarría 1935 - 1973, en http://www.eumed.net/libros-gratis/2013a/1288/index.htm, p. 14.
} 
también en la parte baja, pero separados de la zona residencial por la línea férrea. El equipamiento instalado constó, además, de viviendas, escuelas, iglesia, gimnasio, casinos, economatos, mercados, etc.

En los años 40, la Compañía construyó las últimas viviendas para sus trabajadores, el colectivo "Chollín". La edificación de estos edificios ubicados en el sector Puchoco fue resultado de la urgente demanda habitacional de la época, provocada por los daños que sufrieron los pabellones ya existentes por el terremoto de 1939 y por la llegada de un gran número de obreros que entraron a trabajar al pique Arenas Blancas, cuya excavación se inició en el año 1942. En ello influyó, además, la instalación de nuevos modelos habitacionales en las salitreras del norte del país que modificaron el modelo de ciudad industrial predominante durante las últimas décadas. Así fueron construidos, en primer lugar, tres bloques residenciales, dos de ellos destinados a los obreros y empleados con familia y uno situado al sur poniente, para los obreros solteros; además, de un Apostolado Popular, a cargo de religiosas. Posteriormente fueron agregados dos bloques unifamiliares más. Los colectivos eran de material sólido, "de cuatro pisos divididos en departamentos higiénicos, amplios, con calefacción central, gas y un pequeño baño que incluye ducha" 28 . El colectivo para solteros dispuso de "piezas independientes y baños, además una sala de recreación. Anexo a este colectivo se encuentra el Casino de Obreros, donde obtienen su alimentación a precios controlados" ${ }^{29}$. Este Casino de Obreros existió hasta el año 1961. Las dos primeras plantas de estos bloques, próximas al suelo, fueron habitadas por los empleados de la Compañía, más cómodas en su ingreso. En las plantas número tres y cuatro fueron alojados los obreros, lo cual rompe parcialmente la segregación espacial tan rígida de la primera etapa. Por último, en cuanto al Apostolado Popular, cabe señalar que era "... un espacio en planta libre de dos niveles; el primero destinado a lavandería y el segundo, donde las pobladoras recibían capacitación y además lugar de comidas para los trabajadores solteros" ${ }^{30}$. Los cursos allí dictados estaban dirigidos a las esposas e hijas de los trabajadores y tenían como objetivo formar buenas madres y esposas. Entre los cursos estaban: economía doméstica, tejidos a máquina, peluquería, corte y confección, bordado y clases de moral ${ }^{31}$.

En el caso de Bellavista los directivos alemanes, hasta los años '60, se preocuparon por las condiciones de habitabilidad de sus trabajadores, empleados y obreros. Esto dio origen a la creación de varias poblaciones en el sector Bellavista (población "la Rana", los pabellones de Avenida Latorre, Chorrillos y Miraflores, las casas del sector "Lado Mar" para los empleados). Se construyeron, además diversos equipamientos urbanos como el retén de carabineros, iglesia, escuela, gimnasio, casinos, maternidad, sala cuna, mercados, economatos. Así, se construyó un espacio con un estándar más alto del que tuvieron otros

\footnotetext{
${ }^{28}$ María Díaz Castillo, Labor del Servicio Social en las Compañías Carboníferas de Lota y Schwager en el año 1961, Memoria de Prueba para optar al título de Asistente Social, Universidad de Concepción, Chile, 1962, p. 39.

${ }^{29}$ Ibidem, p. 39.

30 Pablo Fuentes, "Del familisterio al condensador social. El colectivo Chollín como arquetipo moderno". Revista AUS 17, pp. 49-55, p.51

${ }^{31}$ Díaz, op. cit., p. 70.
} 
obreros en la época. Pero, se consolidaba un modelo de segmentación social, creando espacios exclusivos y de mejor calidad para los empleados y técnicos. Los habitantes de este sector disfrutaron de diversos espacios públicos recreativos; entre ellos, el Casino para Empleados, una piscina y una cancha de tenis, parques y jardines. Se construyó la Población Florentina, entre los años 1936 y 1965, la que era concebida por los obreros como un mundo prohibido. Finalmente, durante este periodo de esplendor, específicamente entre los años 1954 y 1957, se construyó la población "La Junta" que fue habitada por el personal administrativo de la fábrica.

Pero el esplendor de las fábricas no logró mantenerse. La industria del carbón comienza su declive hacia fines de los años '50. En 1964, como una forma de enfrentar la crisis de la industria, surge la "Compañía Lota-Schwager S.A." de la fusión de la Compañía Carbonífera y de Fundición Schwager y la Compañía Carbonífera de Lota. Fue un intento por mantener la explotación carbonífera, la que luego se convertiría en una empresa estatal. En el caso de Bellavista, el auge que constituyó el llamado "período de los alemanes" se termina en 1962, cuando el empresario textil Teófilo Yarur compró la fábrica. Allí se inició un período de creciente malestar de los trabajadores/as, lo que se materializó en varias huelgas. Uno de los cambios experimentados fue la existencia de una relación distante con el personal directivo, influyendo en ello la ausencia de Teófilo Yarur de las dependencias de la fábrica, puesto que manejaba sus negocios desde Santiago. También, cambiaron las condiciones laborales, los sueldos se mantuvieron y muchos trabajadores fueron despedidos. Estos fueron motivos suficientes para activar la movilización sindical y realizar numerosas huelgas y tomas de la fábrica. En materia de vivienda, la fábrica se desliga de la construcción de ellas, pasando ésta a manos de entidades gubernamentales ${ }^{32}$.

\section{2- $\quad$ El auge de los trabajadores con el Gobierno de la Unidad Popular (UP)}

Como ya hemos planteado, ambas empresas tuvieron prácticas de paternalismo industrial, lo que se tradujo en políticas empresariales de bienestar social. Sin embargo, esto no significó que las relaciones laborales estuviesen exentas de conflictos. Con algunas diferencias en las trayectorias, en ambas existió una fuerte segregación socio-espacial que marcó la forma de acceso al territorio y a los servicios creados para sus habitantes. Existieron barreras físicas, prohibiciones y guardias que controlaban la circulación por las zonas. El triunfo del gobierno socialista de Salvador Allende en 1970, marca un punto de inflexión muy importante. Ambas industrias fueron estatizadas, lo que llevó a construir nuevas formas de relaciones laborales.

En el caso de la industria textil de Bellavista-Tomé, las relaciones de los trabajadores en la época de administración alemana habían sido bastante cordiales, no exentas de conflictos, pero claramente mejores que las que se experimentaron a partir de 1962 cuando Teófilo Yarur compra la fábrica. Los Yarur tenían un posicionamiento muy importante en la industria textil en Santiago y, al comprar las textiles de la región del Bío-

32 Karla Lagos, "Evolución urbana del barrio industrial Bellavista", Seminario de Título, Carrera de Arquitectura, Universidad de Concepción, 2009, p. 107. 
Bío, se convirtieron en el conglomerado más fuerte de producción textil. Pero aquí no tuvieron un trato cercano con los trabajadores. En el caso de Bellavista, fue durante este período donde se generaron los conflictos laborales más importantes, realizando grandes huelgas, que incluso duraron varios meses y que obligaron la intervención directa del Estado. En el año 1970 se agudizaron los conflictos con varias huelgas y tomas de la fábrica. Los trabajadores/as estuvieron meses sin recibir salarios. En agosto, un conflicto de los obreros metalúrgicos generó una huelga de 24 días, motivando la intervención del Estado

A las 10.30 horas de ayer se puso en vigencia el decreto de reanudación de faenas dictado por el Ministerio del Trabajo en la Fábrica de Paños Bellavista Tomé. La medida afectó a 83 trabajadores de la sección maestranza de la industria, quienes se encontraban atrincherados en el interior de la planta desde hacía varias semanas (...) A la hora indicada, se constituyó en el lugar el inspector provincial del Trabajo, Máximo Torche... [quien] efectuó una revisión de las instalaciones, para comprobar los posibles daños en la maquinaria, lo que no se verificó. ${ }^{33}$

La situación no se solucionó allí, ya que muchas otras secciones también paralizaron. El conflicto se agudizó con el descuento de los días no trabajados. A fines de septiembre, los obreros de Bellavista decidieron marchar a Concepción. Según lo consignado por el diario El Sur, 800 trabajadores marcharían en protesta por el no pago de sueldos, que en algunos trabajadores se extendía desde el mes de julio. La respuesta de la empresa fue argumentar que se habían descompuesto 2 de las 4 calderas que hacían funcionar la fábrica. Por ello "caducó temporalmente los contratos de trabajo a todos los operarios" 34 , con excepción de aquellos que se habían mantenido trabajando aun con la huelga. La elección del candidato de la Unidad Popular a la presidencia abrió para los trabajadores una esperanza, frente a la crítica situación que se vivía. Tal fue el nivel de polarización entre la empresa y los trabajadores/as, que llevaron incluso a estos últimos a que “... en unos comicios en que participaron más de dos mil obreros textiles de la comuna, y donde se acordó pedir al Gobierno la expulsión del país del presidente de la Compañía Teófilo Yarur, por considerar que deliberadamente provoca estos conflictos para despedir personal, lo que viene sucediendo desde hace años ${ }^{35}$.

Los trabajadores/as textiles buscaron generar presión, a fin de lograr la intervención del candidato recién electo. Según expresaron, se incorporarían “...a la concentración de Salvador Allende con el propósito de obtener luego una entrevista con el candidato triunfante en las pasadas elecciones presidenciales"36. A pesar del apoyo gubernamental para mediar en el conflicto y para dar apoyo financiero a través de un préstamo del Banco del Estado a la industria, aun a fines de octubre no se regularizaba la situación. A dos semanas de haberse reintegrado al trabajo, no se les pagaban sus salarios. A mediados de

${ }^{33}$ Diario El Sur, Concepción 15 de agosto de 1970, p. 9.

${ }^{34}$ Diario El Sur, Concepción 26 de septiembre de 1970, p. 9

${ }^{35}$ Diario El Sur, Concepción 6 de septiembre de 1970, p. 13

${ }^{36}$ Diario El Sur, Concepción 26 de septiembre de 1970, p. 9 
noviembre, los dirigentes sindicales se reunieron con el ministro del trabajo, a fin de solicitar la mediación directa del nuevo gobierno.

En ese marco se logró que el Presidente Salvador Allende en una visita a la región en diciembre de 1970, firmara el primer decreto expropiatorio de su gobierno, que afectó a la Industria Textil Bellavista Tomé. Así se ponía fin a un conflicto que se dilataba ya por varios meses e incluso años,

En un discurso que duró seis minutos, el Ministro de Economía puso ayer fin a una serie de conflictos de orden gremial que afectaron a la fábrica Bellavista Tomé en los últimos años, al anunciar oficialmente la expropiación de la industria por el Gobierno (...) La determinación de la administración de Allende la primera que se realiza en el país de esta naturaleza, fue hecha por el Secretario de Estado ante unas dos mil personas, entre trabajadores y familiares, que se congregaron en el interior de la fábrica y calles que dan acceso a la entrada ${ }^{37}$.

El gobierno de la UP usó los mecanismos legales existentes (Decreto 1262 de 1953) que le posibilitaban expropiar todo establecimiento que estuviese en receso. La situación de la fábrica Bellavista lo ameritaba, los dueños habían paralizado ciertas faenas y más aún habían trasladado maquinaria de la fábrica a las otras instalaciones textiles que tenían en Santiago, generando así un perjuicio evidente para sus trabajadores.

En el caso de los trabajadores del carbón, el año 1970 también fue convulsionado. En agosto de ese año los trabajadores de la Compañía de Lota-Schwager votaron la huelga, debido a que no llegaron a acuerdo con la empresa. Los trabajadores solicitaban un alza de los salarios, pero la empresa les ofrecía un $28,7 \%$, lo que estaba muy por debajo de sus expectativas de un $60 \%$. A pesar de la mediación gubernamental, la huelga se hizo efectiva, y duró por varios días, período en el cual la empresa fue mejorando lo ofrecido, pero sin lograr los anhelos de los trabajadores. Un aspecto destacado de esta movilización es que se extendió más allá de los trabajadores carboníferos, creándose el Comando Prodefensa de los Pliegos del Carbón, que era presidido por el alcalde de Coronel Leonardo Carrasco. El 18 de agosto de 1970 el diario El Sur, informaba que a “... este paro - según afirmó el Alcalde - se plegarán todos los gremios en los que se incluyen los servicios de locomoción, Municipalidad, comercio, profesores, médicos y estudiantes secundarios. La resolución adoptada por este organismo, se hará llegar por notas a la gerencia de la Compañía Carbonífera y representantes del Gobierno" 38 .

Dicho comando llamó a paros de 24 horas en más de una oportunidad en el período de conflicto, a fin de presionar por mejorar a propuesta empresarial para los trabajadores del carbón. En Coronel, la situación se transformó en un conflicto de carácter local que agrupó a las organizaciones sociales entre las que se encontraban: los sindicatos de Feria Libre y Mercado, de Matarifes, de Empleados Particulares y de Suplementeros; las asociaciones de microbuseros de la línea urbana Camilo Olavarría, de Comerciantes, de Obreros y Empleados Municipales; la Cámara de Comercio Minorista, la Unión de

\footnotetext{
${ }^{37}$ Diario El Sur, Concepción 2 de diciembre de 1970, p. 9
}

${ }^{38}$ Diario El Sur, Concepción 18 de agosto de 1970, p. 11 
Profesores de Chile; los centros de alumnos de los liceos de Coronel y San Pedro, del Instituto Comercial y la Escuela Industrial de Schwager ${ }^{39}$. Se realizaron asambleas, desfiles y manifestaciones públicas. Incluso se informaba la participación del sacerdote Pierre Dubois, que posteriormente se destacaría en las luchas de los pobladores de Santiago en contra de la dictadura de Pinochet.

El padre Pierre Dubois, que pertenece al Movimiento Obrero Católico, es uno de los más activos participantes en cuanta asamblea realizan los mineros. El religioso integra, representando a los sacerdotes de la zona minera, el Comando Prodefensa de los Pliegos del Carbón. En carácter de tal asistió a la concentración organizada el viernes último por el Comando en la Plaza de Armas y fue uno de los oradores más convincentes para demostrar la justicia de las peticiones gremialistas ${ }^{40}$.

Sin duda, las movilizaciones en la zona del carbón tuvieron siempre un carácter más radical. Allí las dirigencias sindicales eran de los partidos políticos de izquierda, autodefiniéndose como una "zona roja". Por lo que no es de extrañar que, aun cuando finalmente llegaran a un acuerdo con la Compañía en relación al reajuste salarial, los conflictos no cesaron. Después del triunfo de la UP en las elecciones del 4 de septiembre, decidieron sumarse al llamado al “... paro nacional decretado por la Central Única de Trabajadores en el caso de que en la votación del Congreso Nacional no se reconozca como presidente electo al doctor Salvador Allende triunfador de las elecciones pasadas. El paro preparado por este organismo se halla anunciado para el día siguiente, en el supuesto caso de que esto sucediera" 41 .

Una vez instalado el gobierno de la UP, se avanzó rápidamente hacia la estatización de la producción carbonífera. El 31 de diciembre de 1970, fue el mimo presidente quien, en un acto en la Plaza Arturo Prat de Lota donde asistieron unas 6.000 personas, formalizó la estatización de la Compañía Lota-Schwager S.A., siendo administrada por CORFO. Habló el dirigente de los mineros Juan Bautista Bravo

Los trabajadores del carbón saludamos jubilosos este acto del Gobierno Popular y estamos aquí para dar todo nuestro apoyo a esta idea y dejar muy en claro que estamos conscientes de las nuevas y grandes responsabilidades que nos echamos encima al tomar en nuestras manos la dirección de estas empresas (...) Compañero Presidente, en el nombre de los sindicatos de la empresa Lota-Schwager, de la clase trabajadora y de los pueblos de Coronel y Lota doy a usted una calurosa bienvenida y entrego a usted y al Gobierno de la Unidad Popular el apoyo solidario de los trabajadores del carbón a todas las medidas que disponga ${ }^{42}$.

\footnotetext{
${ }^{39}$ Diario El Sur, Concepción 23 de agosto de 1970, p. 9

${ }^{40}$ Diario El Sur, Concepción 24 de agosto de 1970, p. 11

${ }^{41}$ Diario El Sur, Concepción 14 de octubre de 1970, p. 10

${ }^{42}$ Diario El Sur, Concepción 1 de enero de 1971, p. 5
} 
En enero de 1971, asumió el nuevo gerente general de la empresa estatizada, Isidoro Carrillo, quien era un ex dirigente minero y al momento de ser nombrado, se desempeñaba como regidor. En el acto en Coronel, Carrillo subrayó el compromiso del gobierno por mejorar las condiciones de los trabajadores, pero apeló también a la responsabilidad de estos en el futuro desarrollo de la empresa ${ }^{43}$.

Durante los años de la UP también hubo algunos conflictos laborales. En 1971 la discusión del pliego de peticiones motivó una huelga que duró algunos días, pero finalmente se firmó el acuerdo. Existía confianza en que se obtendrían respuestas a sus justas demandas, sobre todo considerando que la contraparte era "un exdirigente minero y un genuino trabajador que sabe aquilatar las necesidades de su propia clase" 44 . A ello se sumaba la preocupación de la baja de la producción, provocada por los días de huelga y el aumento del ausentismo laboral. Según la dirigencia sindical esto

... ha sido poco menos que trágico para el proceso revolucionario que sustenta el Gobierno del compañero Presidente. No se puede exigir un mejoramiento sustancial en sueldos y salarios, mientras no desaparezca este fenómeno laboral. El trabajador debe meditar esta grave situación, caso contrario la economía de la industria irá desfalleciendo para asegurar los recursos del nuevo reajuste que debe otorgarles a los trabajadores a contar del próximo año ${ }^{45}$.

La mayoría de los trabajadores/as de ambas empresas percibieron este período como una posibilidad de mejoramiento en sus condiciones de vida. Además, fue visto como un período de esperanza, por el cambio radical de las condiciones de la clase trabajadora. Aunque con el paso del tiempo, hacen también una autocrítica.

Los trabajadores/as de la fábrica Bellavista de Tomé le otorgan a este período un significado profundo, porque se comienza a experimentar un cambio, no solo en términos de la estructura laboral, sino también en términos culturales. Uno de los aspectos más significativos fue la apertura de los espacios, terminando con décadas de segregación social, lo que marca la memoria histórica del período. Eso significó la democratización de los lugares que antes eran de uso exclusivo de empleados y de la gerencia. Uno de los ejemplos emblemáticos fue el uso de la piscina que, de un espacio prohibido, paso a ser el símbolo de que en ese momento eran todos iguales. Sin embargo, es interesante ver como hoy hacen una autocrítica a esa experiencia

... cuando sube Allende al gobierno y cambia toda la historia, pero cambia tan brusca que como sacamos la barrera para poder entrar. Y claro, la administración de la fábrica dice no, ahora todos se pueden ir a bañar a la piscina y quedó la crema, porque no había disciplina en nosotros y nos fuimos a bañar en la piscina que se bañaban ellos. Obvio pos, si nosotros los invadimos, no nos lavábamos los pies, no nos duchábamos y nos tirábamos así mismo, con los trajes de baño medios malos y claro, fue un

\footnotetext{
${ }^{43}$ Diario El Sur, Concepción 14 de enero de 1971, p. 8

${ }^{44}$ Idem

${ }^{45}$ Diario El Sur, Concepción 6 de agosto de 1971, p. 12
} 
escándalo, yo creo que en el país provocó, yo lo asocio lo que nosotros vivimos el 70 aquí, creo que pasó en todo Chile. Fue un despertar, una cosa que era algo distinto y que ahora que somos iguales y no éramos iguales, pero nosotros creíamos que éramos iguales y esa fue la cosa, yo creo, que hubo un cambio tan grande en Bellavista, porque como le explicábamos, todo aquí era privado ${ }^{46}$.

Existe la percepción de que los cambios fueron muy rápido y el tiempo muy corto para asimilar una nueva forma de entender las relaciones entre capital y trabajo. De un patrón entendido como un enemigo de clase, a sentirse responsables directamente de la fábrica. En ese momento, se creía en la posibilidad de un futuro, que implicara un cambio en las formas de vida. Uno de los aspectos relevados de manera muy positiva fueron los planes de alfabetización, que además abría las posibilidades de capacitación.

En Tomé se generaron planes de alfabetización, pero el primer obstáculo fue convencer a los trabajadores/as de reconocer su necesidad

... la gente no quería porque tenía vergüenza porque la gente andaba pituquita, toda bien pinteada porque aquí todos andábamos bien vestidos por, por las telas. Pero la gente, cómo socialmente iba a decir yo no sé leer, porque nadie podía decir este no sabe leer, a lo mejor el compañero más cercano, el familiar y me decía a mí, mijito me decía, pero es que yo no sé leer y me da vergüenza. Pero por qué le da vergüenza y ahí, manejo, manejo, manejo, hasta que lográbamos convencer y, empezamos a meter gente a estudiar y estudió harta gente en alfabetización y logramos un avance importante... ${ }^{47}$

La experiencia que se vivió fue muy significativa, ya que por primera vez en la historia los trabajadores sintieron que era posible cambiar las formas de vida y avanzar hacia una verdadera democratización de la sociedad. Eso es recordado con emoción

... fue el setenta y uno, me mandaron a Santiago, hice una capacitación aquí en Concepción, un poco en Santiago, estuve quince días, me preparé un poco y el ingeniero fue el que influyó en la administración de ese tiempo que me nombrara a mí encargado de esa oficina de capacitación. Y cuál era el papel de esa oficina, hacer un estudio general de la fábrica, de qué era necesario para los trabajadores. Yo me metí harto en la cosa. Partimos haciendo un estudio, después un programa de capacitación en alfabetización de los obreros, creo que alfabetizamos más de doscientos, trescientos más o menos porque había harta gente que no sabe leer ni escribir adentro de la fábrica y había gente que de sesenta años que aprendió a leer ahí, fue bien emocionante esa cuestión. Y, además, después fui ascendiendo en él, en las necesidades, hicimos supervisión, cursos de supervisión a los jefes de la fábrica, a todos los jefes, del más grande hasta el más chico ${ }^{48}$.

\footnotetext{
46 Taller de Hombres, Bellavista. Segundo Semestre de 2014.

${ }^{47}$ Relato de Vida No1, Bellavista-Tomé, Segundo Semestre de 2014.

${ }^{48}$ Ibidem
} 
La situación se repetía en el mundo del carbón. La capacitación y los planes de nivelación de estudios forman parte de los elementos que relevan los extrabajadores de la empresa

... la capacitación en Schwager en general en ENACAR que en ese tiempo era Schwager y Lota empezó más o menos en los años 70 ya hablando de una capacitación más seria. Se creó un departamento de capacitación ese año e inclusive partieron ellos enseñándoles elevando el nivel de escolaridad de los mineros, especialmente el de los supervisores. Entonces hubo cursos en los cuales se enseñaba hasta castellano, me estoy refiriendo en esa época. Después del 73 - 74 en adelante más o menos ya se creó una capacitación más dirigida al trabajo, a la operación ${ }^{49}$

El plan de alfabetización fue una iniciativa dirigida desde el gobierno hacia los trabajadores. En 1971 bajo el título de "Enseñanza Básica para los Trabajadores Textiles" la prensa local se refería así a los planes a inaugurar en Tomé

Quedo inaugurado en el puerto, el Curso Experimental de Educación Básica para trabajadores, de la empresa Paños Oveja y bajo la dirección de Edith Mora Ramírez quien ha sido designada para estas funciones por el Ministerio de Educación que patrocina estos cursos, los que también se dictarán en Paños Bellavista, Fiap y Empresa Conservera Camanchaca (...) Este curso ofrece una oportunidad educativa a aquellos trabajadores que no han completado sus estudios básicos; la enseñanza se realizará a través del estudio de problemas reales y las unidades proyectadas son, nutrición, desarrollo histórico y social, lengua materna, matemáticas, el trabajo, orientación técnica y actividades coprogramáticas ${ }^{50}$.

Los trabajadores carboníferos con la creación de ENACAR (Empresa Nacional del Carbón), alcanzaron mejoras importantes en sus condiciones de trabajo. Esta actividad tenía mucho riesgo y la historia de los mineros se caracterizó por la latencia de los accidentes provocados por explosiones de gas grisú, lo que dejó muchos muertos a lo largo de más de un siglo de existencia. Si bien desde temprano la empresa se preocupó por generar políticas de seguridad, esto fue absolutamente ineficaz y los trabajadores continuamente criticaban las condiciones infrahumanas en las cuales trabajaban, extrayendo el carbón en el subsuelo marino. En el período de la UP los trabajadores relevan como uno de los aspectos significativos la seguridad y la capacitación. Al parecer se sienten parte de un proceso en el cual su seguridad, en tanto mineros, era importante

Entonces cuando uno entraba a la Compañía del carbón había un equipo de instrucción, lo que te dije yo. Instructores, mecánico, eléctrico, minero y primero auxilios. Esos los tenía la Compañía del Carbón por una política de seguridad - que le

\footnotetext{
${ }^{49}$ Relato de Vida No 1 , Puchoco- Schwager, Primer Semestre de 2015.

${ }^{50}$ Diario El Sur, Concepción 29 de agosto de 1971, p. 18
} 
decían ellos - para poder manejar todo el sistema. Entonces a cada uno lo mandaban (...) Eso comenzó a correr desde los años 70, había instrucciones de seguridad, como este libro que tengo acá (...) [Antes] no existían. Aquí sale todo lo relacionado con el trabajo ahora. Que es el peligro, políticas de medio ambiente, todo esto que ves acá se lo enseñaban a uno en la compañía. Que es un accidente. La ley 1744. De ahí empezó a correr todo este sistema de las políticas de seguridad ${ }^{51}$

Una de las cuestiones que también se destaca es el hecho de que en ese período se trabajaba más de manera colectiva, existía un sentido de comunidad. Las relaciones sociales al interior de la faena productiva se hicieron más humanas, se reconocían cuáles eran los problemas y se intentaba buscar soluciones colectivas para ellas.

...por ejemplo, había un problema en una sección determinada, íbamos con el jefe yo le decía con el ingeniero... hablábamos con el jefe de la sección, decíamos qué necesidades cree usted que tiene... Don Mario Aguayo era ingeniero, entonces me decía a mí, es que ahí está el problema..., pedíamos permiso al jefe, veíamos todos los movimientos de ellos, mira, ese hombre ha ido como tres veces con la misma pieza y ha vuelto con la misma pieza y ha hecho esto, esto y esto otro y no sabemos por qué, entonces íbamos y preguntábamos por qué se daba eso, entonces ahí faltaba racionalizar la pega y hacerla más ordenada para que la producción fuera mejor. [también] había que humanizar más la supervisión o sea no era na tanto así la huasca sino que ahora, el tiempo de la UP po', o sea era más humana la cosa, pero ese era el propósito, por lo tanto había que racionalizar más y decir no po' ahora por favor o hagámoslo, pero hagámoslo en equipo y no, no es que usted lo hace porque usted lo hace, no, no, tiene que haber una razón, entonces logramos hartas cosas ${ }^{52}$.

El cambio de vida fue evidente, les permitió estudiar, dignificarse como trabajadores a partir de un trato distinto con los jefes

Hice un curso de nivelación de estudio de enseñanza media, yo no tenía enseñanza media, tenía segundo medio y el ingeniero me decía, no, es que tú tení habilidad, conocís todo el proceso en la fábrica me decía, tu estai pintao pa esto. Pero es que jefe yo no soy, yo no tengo ni estudios, pero tení habilidades que no tienen otros me dice, me decía él, ya po', y los lanzamos, hicimos un convenio con la Universidad Técnica del Estado (UTE), con INACAP y con la industria para hacer una nivelación de enseñanza media que no fue poco. O sea, hoy día uno lo mide fue importantísimo lo hicimos porque en ese tiempo lo miraba como a huevo la gente pero esa gente que fueron veintidós y tanto que lo titulamos con la enseñanza media nunca habíamos logrado tener enseñanza media siendo obreros y lo logramos, incluso, dos de ellos postularon a la universidad y uno ahora es técnico..., es jefe de la maestranza él todavía" 53 .

\footnotetext{
${ }^{51}$ Relato de Vida No 2 Puchoco-Schwager, Primer Semestre de 2015.

${ }^{52}$ Relato de Vida No 1, Bellavista-Tomé, Segundo Semestre de 2014.

${ }^{53}$ Ibidem
} 
La educación fue un elemento central en el objetivo de otorgar mejores condiciones de vida y de trabajo. Esta no solo estaba dirigida a los planes de alfabetización, nivelación de estudios o capacitación laboral. Sino que existió la posibilidad de realizar estudios superiores, lo cual era un paso muy importante en la movilidad social de los obreros. En el caso del carbón, incluso se planificó la creación de la Universidad del Carbón que fue inaugurada oficialmente por el propio Presidente Allende el 30 de mayo de 1971 y que funcionaría simultáneamente en Lota y Coronel $^{54}$.

\section{La caída de los trabajadores con la dictadura cívico-militar y el despojo neoliberal}

En el mundo del carbón se sintió con mucha fuerza la represión de la dictadura, debido a la existencia de un mundo sindical más inclinado hacia la izquierda. Ellos mismos lo reconocen al plantear que la represión era porque "todos éramos de izquierda". Los militares se hicieron cargo directamente de ENACAR, los sindicatos fueron intervenidos, hubo muertes y desapariciones, delaciones de compañeros, etc. Entre ellos fue detenido el gerente de ENACAR Isidoro Carrillo y ejecutado el 22 de octubre de 1973.

Después del golpe de estado los sindicatos perdieron fuerza. Porque hubo muchas persecuciones. Encarcelaron a varias personas, mataron personas, es lo que es nomas, todos sabemos lo que pasó el golpe de estado, como fue. Fue algo fuerte, yo lo viví, tenía 18 años y hubo persecuciones, lo dieron hasta en la tele, para que les vamos a dar más cuento. Entonces ahí los sindicatos perdieron fuerza por temor, muchos se retiraron o los despidieron de la empresa. Me acuerdo que echaron en Lota al sindicato número 5, echaron a todos los dirigentes..., como eran miristas los echó de la empresa.

Para el golpe no había sindicato, dejo de funcionar (...) Los tomaron presos nomas. Les veían el currículum y algunos los largaban y otros quedaban adentro. Muchas veces la persona no iba metida en nada y cualquier persona lo acusaba que esa persona era comunista. Y quedaba complicado. Porque uno alegaba sus derechos y quedaba de comunista. Entonces quedó ese temor ${ }^{55}$

En Bellavista Tomé, también sufrieron represión, que se tradujo en incertidumbre en relación al futuro de la empresa. También los dirigentes sindicales fueron detenidos

... los dirigentes, se los llevaron al estadio regional y después se los llevaron a Santiago... el problema es que en ese momento carecíamos totalmente de las comunicaciones, no se sabía que podía pasar, solamente que la gente andaba diciendo que andaban buscando a los dirigentes para matarlos y a los trabajadores más metidos entonces todo el mundo quedó con los brazos cruzados porque ya se vinieron todos aquí a intervenir dentro de la comuna, los marinos y los carabineros por el toque de queda ${ }^{56}$.

\footnotetext{
${ }^{54}$ Diario El Sur, Concepción 30 de mayo de 1971, p. 5

55 Taller de Hombres, Puchoco-Schwager, Primer Semestre de 2015.

${ }^{56}$ Entrevista No 1, Extrabajor de Bellavista-Tomé, Primer Semestre de 2016.
} 
En el caso de la industria del carbón en Schwager, la crisis se fue haciendo cada vez más evidente. A pesar de la fuerte represión en la zona, se generaron igual conflictos laborales. Los sindicatos no desaparecieron, pero fueron intervenidos y fueron perdiendo la fuerza reivindicativa. "... para que la gente no creyera que era tan dura la dictadura. Los dirigentes que estaban la dictadura los colocó, para que no dijeran que era malo el gobierno, que no había libertad"57.

En el relato de los trabajadores en Tomé se reconoce que hubo represión inmediatamente después del golpe de estado. Hay relatos de detenciones, de listas negras. Se recuerda que hubo gente que fue detenida, pero después cuando la soltaban, volvía a trabajar a la fábrica. En lo que, si hay coincidencia en ambas experiencias industriales, es el que en período de dictadura se perdieron beneficios y regalías alcanzados con la lucha sindical. Por ejemplo, en Tomé, las mujeres recuerdan que se perdió el derecho a la Sala Cuna.

En el período inmediatamente después del Golpe de Estado, la fábrica es intervenida por los militares. La decisión era privatizarla. En el año 1975, se licita y son los mismos trabajadores quienes a través de una cooperativa se hacen cargo de la industria. Para ello utilizaron los recursos de las indemnizaciones adeudadas desde la época de Yarur, que fueron ganadas tras un proceso judicial y un préstamo de Instituto de Financiamiento Cooperativo - IFICOOP. La compra se materializó en 1977, al constituirse la Cooperativa de Trabajo Fábrica de Paños Bellavista Tomé. La administración misma de la fábrica no la hicieron directamente los trabajadores, ya que la CORFO designó un gerente general ${ }^{58}$. Pero las posibilidades de reactivar la producción, en un contexto de apertura de los mercados a productos importados, hizo que la situación se tornara imposible de remontar. Se requerían mayores capitales y para acceder a préstamos se requería el aval del Estado, cuestión que no lograron, quebrando la cooperativa en 1979.

Por qué se terminó la cooperativa. Resulta que los fondos que recibía la cooperativa en el país, venían del Instituto Nacional de Cooperativas- IFICOOP, esa es la sigla y los fondos que ellos recibían, venían de afuera, venían principalmente de Alemania porque esta política es una política de la democracia cristiana, de las cooperativas entonces ellos aumentaron digamos el interés por eso y ayudaron harto y qué paso, según el gobierno se enteró que los dineros, los fondos que llegaban de allá no iban para las cooperativa sino que muchas iban a grupos terroristas, grupos políticos, para lograr, digamos ir en contra de él, entonces que hizo eliminó, eliminó, cortó la ayuda de Europa, en este caso de Alemania a Chile y con eso nos estranguló a nosotros como cooperativa y ahí sonamos. Esa fue la quiebra de la cooperativa para mí. No fue una quiebra de que nosotros manejábamos mal, que no éramos eficientes, no, porque la eficiencia existió, fue buena. Cortaron la alimentación económica para seguir trabajando ${ }^{59}$.

\footnotetext{
${ }^{57}$ Relato de Vida No 1, Puchoco- Schwager, Primer Semestre de 2015.

${ }^{58}$ Magdalena Saldaña, “Coser y ¿Cantar? La quiebra de 2007 en la voz de los trabajadores”. En Cartes et all, op. cit., pp 113-130.

${ }^{59}$ Entrevista $N^{\circ}$ 1, Extrabajador Bellavista Tomé, Primer Semestre de 2016
} 
En 1982 el empresario Hernán Ascuí compra la fábrica a la cooperativa y se experimenta un período de prosperidad, al comprar también la fábrica de Paños Oveja. La fusión de ambas industrias, dio origen a la Fábrica Bellavista-Oveja Tomé. En 2002 cambió nuevamente de dueño pasando a manos de la sociedad de Cristóbal Kaufmann, Miguel Otero y Gabriel Berczely, quienes la mantuvieron productiva hasta declararse definitivamente en quiebra en el año $2007^{60}$. Para los extrabajadores/as fueron años duros. Manifiestan que "no teníamos ni que comer", no se pagaron imposiciones y por lo tanto las jubilaciones fueron muy bajas. Se generaron muchas movilizaciones sociales que alcanzaron alta notoriedad local y nacional, con intentos de mediación del Arzobispado de Concepción $^{61}$. En 2010 la fábrica fue adquirida por el grupo Sabat, quienes la mantienen en funcionamiento hasta hoy, pero a una escala muy reducida. De los miles de trabajadores que la empresa tuvo a comienzos de los años '70, hoy no cuenta con más de 30.

La quiebra de la fábrica en Tomé, no se debió al agotamiento del recurso, ni a la falta de mercados. La producción de telas de alta calidad, era el orgullo de sus trabajadores. Sin embargo, la política de apertura hacia los mercados internacionales y la nula protección estatal, hicieron que la producción de telas nacionales fuera paulatinamente desapareciendo. Era imposible competir con los precios de los productos chinos. Además, la crisis económica de los años '80 golpeó los hogares e hizo que se restringieran las posibilidades de consumo. Así, el orgullo de ser los obreros "mejores vestidos del país", fue cambiando. Los salarios tendieron a ser cada vez más bajos y por lo tanto se hizo indispensable abaratar el costo de la vida. El consecuente empobrecimiento de las condiciones materiales de vida se mitigaba favoreciendo la entrada de los productos chinos de bajo costo.

En el caso del carbón, ENACAR siguió existiendo, pero comienza paulatinamente a debilitarse como estructura productiva. Las minas de Lota se mantuvieron estatales hasta su cierre en 1997. Schwager pasó en 1979 ser una filial de ENACAR, con el nombre de Carbonífera Schwager S.A. En 1986 pasa a ser una sociedad anónima abierta, hasta que el año 1989 se privatizó completamente. Según el discurso de los ex trabajadores, fueron los Chicago Boys quienes idearon la desaparición del mundo minero del carbón. No hubo intenciones en dictadura de invertir en la producción del mineral y la dejaron morir.

¿Por qué? Porque digamos que el tejemaneje que hicieron los tipos fue pescar toda la empresa y venderla a privados, hacer un negocio, porque eso era el objetivo, convertirla en un negocio para que fuera rentable ¿para quién? ¿para la gente? Para ellos pos, ... ¿A quienes les convenía? Les convenía a los compadres que tenían flotas pesqueras, flotas navieras ¿Por qué? Porque hay un muelle aquí y ese muelle, puta valía más que la mina. Y ahí tiene, quienes la AGUNSA, la empresa naviera de Valparaíso y ellos pusieron mayor capital, y se vendió la empresa y empezó a ser sociedad anónima con varios accionistas, donde el accionista principal era AGUNSA, por lo tanto, eran los dueños, los que administraban. Y esos caballeros no tenían el norte de que la mina siguiera por los siglos de los siglos, no, le dieron el plazo que le

\footnotetext{
${ }^{60}$ Rodrigo Luppi San Martín, “Con el alma en un hilo. Los difíciles años: 1970-2011”. En Cartes et all, op. cit., pp. 51-65.

${ }^{61}$ Mayor información sobre el proceso en Saldaña, op. cit.
} 
dieron, de aquí a diez años, doce años esta cosa se tiene que acabar. En vez de carbón vamos a tener chip, y vamos a tener un muelle donde vamos a traer carbón de afuera y vamos a entregar chip y todo lo demás para afuera ${ }^{62}$.

Desde un punto de vista más estructural, la crisis del carbón es anterior incluso al mismo golpe de Estado. ENACAR subvencionaba la producción, basado en que este mineral era una fuente de sustento para miles de familias chilenas $\mathrm{y}$, aunque producirlo era más caro, primaron las políticas proteccionistas. Sin embargo, bajo un modelo neoliberal, no hubo voluntad política para mantener la actividad, sus precios no eran competitivos y la diversificación energética hizo que el carbón perdiera los mercados compradores. En 1981, aun en un ambiente de miedo por la represión de la dictadura, los trabajadores hicieron una huelga por reivindicaciones laborales, logrando mejorar en algo su precaria condición.

El 30 de septiembre de 1994, en el período de post-dictadura, bajo el gobierno de Eduardo Frei Ruiz-Tagle, se produjo una explosión de gas grisú, donde murieron 21 trabajadores. Esto motivó una huelga de trabajadores y la toma de uno de los piques que mantuvo a una gran cantidad de ellos al interior de la mina por 12 días. Finalmente, se decidió que no existían condiciones de seguridad para seguir con la explotación minera y se cerró la industria del carbón en Schwager.

Los gobiernos de la transición, a partir del año 1991, idearon un plan de Reconversión Laboral para la zona, ante el término inminente de la actividad carbonífera. Estaban conscientes de lo que significaría su término para la población, que había vivido por más de 100 años del carbón. El Plan comienza con la Reconversión Laboral a partir del año 1992, con la creación de la Agencia de Reconversión Productiva de la Zona del Carbón - AGECA. El objetivo era reorientar económicamente hacia la actividad forestal y portuaria y capacitar a la población para una nueva reinserción laboral. El organismo encargado fue la CORFO, apoyado por el Servicio Nacional de Capacitación y EmpleoSENCE, Servicio de Cooperación Técnica-SERCOTEC y supervisados por la Contraloría General de la República. Lo que se esperaba era estimular la inversión privada y de esa manera diversificar el empleo. La Agencia no invertía productivamente, aunque si asesoraba y evaluaba las condiciones de infraestructura. Mediante leyes especiales $\left(\mathrm{N}^{\circ}\right.$ 19.129 de febrero de 1992 y las modificaciones en octubre con la Ley $\mathrm{N}^{\mathrm{o}}$ 19.173) se buscaba avanzar hacia políticas de cierre más paulatinas, incentivando el retiro voluntario, la jubilación anticipada, reconversión laboral a través de capacitación, becas y entrega de herramientas ${ }^{63}$. La evaluación que se ha hecho de las políticas de reconversión por especialistas ${ }^{64}$ ha sido en general negativa. Debido a la mala coordinación entre los organismos del Estado y la inversión privada, no se dinamizó la economía local, ni se dieron más posibilidades de empleo. También la evaluación de los habitantes de la comuna

\footnotetext{
${ }^{62}$ Ibidem

${ }^{63}$ Mayor información sobre el proceso en Mariala Lavoz y Silvia Shejade, La experiencia de un proceso. Percepciones de los hombres y mujeres de Coronel acerca de la reconversión laboral y productiva. Seminario de Título, Carrera de Pedagogía en Historia y Geografía. Universidad de Concepción, 2010.

${ }^{64}$ Muñoz. O. “Algunas Reflexiones Sobre la Política de Reconversión en la Industria del Carbón”, Colección de estudios CIEPLAN N 41. Diciembre de 1995. CIEPLAN, Santiago.
} 
hasta el día de hoy sigue siendo negativa ${ }^{65}$. El cierre de las minas de carbón dejó al territorio con altos niveles de cesantía. En 1998 en Coronel, esta alcanzó a 19,7\%.

La percepción de los trabajadores, fue de incertidumbre. Al comienzo tanto ellos y sus familias sintieron alivio de no tener que "meterse al hoyo" otra vez, de no tener que vivir con la angustia de posibles accidentes y no saber si su ser querido llegaría de vuelta a la casa. Pero al poco tiempo la falta de trabajo, la ineficacia de los planes de reconversión, dejó a la gente con una sensación de estar a la deriva, con una mayor precariedad

...fue lamentable porque mucha gente se sintió mal porque como que ese era un trabajo seguro, todos teníamos y nos mirábamos como un trabajo de nunca acabar y cuando se cerró la empresa nos quedamos con las manos cortadas. Todos nos quedamos así, nadie podía hacer nada, pucha nos cortaron las manos... Eso no lo vamos a desconocer, mientras existió eso en el carbón la gente podía decir que estaba conforme, todos estaba contento, el que trabajaba en la empresa del carbón era un buen trabajo, todos miraban como un buen trabajo porque daba para sobrevivir, no así tan satisfactoriamente, pero había una seguridad en los hogares, pero cuando se produjo el cierre, aquí lloraba gente, puta yo igual ${ }^{66}$.

\section{Reflexiones Finales}

La situación de prosperidad del período de mayor auge del paternalismo industrial se recuerda como una memoria viva en las comunidades. Estas ven con cierta añoranza la existencia de una vida segura y donde tanto las necesidades básicas, como la entretención, estaban aseguradas. Ambas comunidades relevan la existencia del gimnasio para las actividades deportivas o la existencia del cine, que les posibilitaba estar al tanto de los estrenos cinematográficos. A pesar de la existencia de una alta conflictividad social y laboral, particularmente en el caso de la industria carbonífera, los habitantes actuales de los barrios industriales relevan los beneficios recibidos de la empresa, mostrando la importancia que tuvieron las prácticas paternalistas ${ }^{67}$.

\footnotetext{
${ }^{65}$ En un estudio realizado por Alejandra Brito, Rodrigo Ganter y Marcos Muñoz del Departamento de Sociología de la Universidad de Concepción, en 2008 se aplicó una encuesta, utilizando el muestreo aleatorio estratificado por unidades vecinales, de acuerdo al PLADECO de Coronel. Los resultados de ese estudio mostraron que un $77 \%$ considera que los cursos recibidos le sirvieron Nada, Casi Nada, Poco. La conclusión de ese estudio es que la política fue un fracaso porque no se realizó un estudio profundo de las necesidades de la población, no incluyeron las dimensiones socioculturales y se hizo sin ninguna participación ciudadana. Brito, Ganter, Muñoz. Informe Final: "Estudio sobre la transformación Socio-cultural en la comuna de Coronel”. Departamento de Sociología, Universidad de Concepción, 2009. MIMEO.

${ }^{66}$ Relato de Vida No 1, Puchoco- Schwager, Primer Semestre de 2015.

${ }^{67}$ Mayor información sobre las percepciones de los actuales habitantes de los barrios industriales, en Rodrigo Ganter, Alejandra Brito, "Cartografías de lo cotidiano: usos, relatos y disposiciones del espacio en el contexto de la industria minera y textil del Gran Concepción (1940-1973)". Revista Austral de Ciencias Sociales No:33 (en prensa).
} 
En la actualidad los mineros y sus familias, ven la destrucción de todo aquello que les generó orgullo y que les recordaba su pasado de esplendor paternalista. "Se fue perdiendo todo lo que Schwager era", al echar abajo los Pabellones (típica construcción obrera) se pierde identidad y sobre todo, reconocimiento de su pasado. Para ellos y ellas "antes del golpe era bonito Schwager había cultura, deporte". Existe la percepción de que ahora "está muerto", no hay esperanzas, no hay futuro para los jóvenes, los que al no contar con buenos niveles de estudio y de inserción laboral, son presa fácil de las redes de narcotráfico. A pesar de tener conciencia de que la vida en la mina no era fácil, a la larga "meterse al hoyo" era algo seguro, por eso sienten que les cortaron las manos.

El futuro en el mundo del carbón se ve incierto, las posibilidades de recobrar una fuente laboral segura son casi nulas y los altos niveles de cesantía hacen el camino muy difícil. Como muchas comunidades industriales, atesoran sus ruinas, pensando que una salida a la crisis es el turismo. Sin embargo, donde antes hubo un economato, un gimnasio, un teatro, hoy solo quedan las ruinas, haciendo más evidente el sentimiento de desesperanza. Casi lo único que lograron recuperar fue el Colectivo Chollín, un conjunto de departamentos con una construcción modernista de gran envergadura. Antes de que la carbonífera pasara a ser completamente privada, ENACAR les ofreció a los trabajadores o sus descendientes comprar los departamentos a un precio muy bajo, pagaderos a 10 años. "Tenían harto que arreglar, y la empresa reponía solo la taza del baño y las puertas, pero aun así salía conveniente. Lo pagué en 4 años, fue una buena inversión"68. En el año 2010, el Consejo de Monumentos Nacionales a través del Decreto 220 de 31 de mayo, le otorga el reconocimiento de Zona Típica, destacando que “... como valor paisajístico se destaca la transformación del territorio como consecuencia de la industrialización, basada en la implementación del modelo urbano de ciudad minera que se adapta a su geografía, en el presente los hitos de infraestructura conforman señas de identidad en el contexto urbano..." 69 . El Programa de Recuperación de Barrios del Ministerio de Vivienda y Urbanismo incorporó al territorio dentro de sus programas, se eligieron de manera participativa las obras de recuperación y se trabajó desde el 2008 con los vecinos/as. Los planes de reconstrucción tras el terremoto del 2010, generaron recursos para el mejoramiento de los departamentos del Colectivo Chollín. En los últimos dos años se han arreglado los departamentos; sin embargo, no existe una política clara destinada a mejorar o reconstruir espacios públicos, lo cual produce un deterioro del tejido social construido a lo largo de más de un siglo de historia. Gran parte de la infraestructura construida por la carbonífera en el barrio se encuentra destruida o cercana a la destrucción, por lo cual las posibilidades de reconstrucción de espacios comunitarios, con carácter patrimonial, son escasos, pero a pesar de ello, sus habitantes mantienen viva la memoria, a través de sus organizaciones sociales.

\footnotetext{
${ }^{68}$ Testimonio de Luis Flores, citado en Programa de Recuperación de Barrios, Historia del Barrio PuchocoSchwager Coronel. Mi barrio, una historia para compartir. Ministerio de Vivienda y Urbanismo, Secretaría regional Ministerial del Bío-Bío, Concepción, 2011, p. 67

${ }^{69}$ Consejo de Monumentos Nacionales. Decreto 220 - 31.05.2010. Declara Zona Típica o Pintoresca el sector Puchoco-Schwager ubicado en la comuna de Coronel, Provincia Concepción, de la VIII Región del Bío-Bío. www.monumentos.cl
} 
En Bellavista hay un pasado reciente que se añora, lo cual se ve favorecido por el hecho que hoy extrabajadores/as y sus descendientes, siguen habitando las poblaciones creadas por la industria. Con la quiebra de la industria, las viviendas pasaron a ser de quienes las habitaban. En acuerdo con las autoridades de gobierno y utilizando como criterio el que las casas le pertenecían al Estado, (habían sido construidas respondiendo la ley de los años '40 que obligaba a las industrias a invertir el 5\% de las utilidades en viviendas para los trabajadores), lograron a través de las dirigencias sindicales acordar un precio de las casas, las cuales fueron pagadas en un determinado número de años. El futuro es, paradojalmente, más abierto y las posibilidades en relación al turismo más reales, al ser una comunidad costera, con balnearios que tienen mucha afluencia de público. Incluso, algunos mantienen la esperanza de reabrir la fábrica y volver a la producción de telas de calidad, que vistieron orgullosamente a los chilenos. La creación de organizaciones de rescate patrimonial, como el Consejo del Patrimonio de Tomé y la Mesa Ciudadana de Tomé, han realizado un importante trabajo ciudadano que tiene por objeto la puesta en valor del patrimonio industrial. Existe por tanto un tejido social, compuesto por ex trabajadores/as y sus descendientes, profesionales, artistas y vecinos que están haciendo un trabajo de concientización sobre la importancia de rescatar los vestigios materiales e inmateriales del período de auge de las industrias textiles en el territorio. En abril de 2016 el Consejo de Monumentos Nacionales, declaró las instalaciones de la Fábrica BellavistaTomé Monumento Nacional. Son 6 hectáreas de construcciones que constituyen una verdadera ciudadela, alrededor de la cual existen una serie de poblaciones construidas por la fábrica en distintos momentos de su historia. Sin embargo, los actuales dueños (un banco y sus arrendatarios), que aún conservan una actividad productiva a muy baja escala, impugnaron judicialmente dicha declaratoria, apelando ante el Tribunal Constitucional, quien falló, finalmente en su contra. Con este fallo, a más de un año de la declaratoria, se logró completar el trámite y el Consejo de Monumentos, a través del Decreto 0166 de 31 de julio de 2017, oficializó el carácter de Monumento Nacional a la Fábrica Bellavista Oveja Tomé, argumentando su decisión en el hecho de ser esta fábrica “...uno de los máximos exponentes de arquitectura industrial en el país (...) Es parte de la memoria social y un vestigio material de la vida cotidiana de los tomecinos (...) Que, no hay un ejemplo similar de una fábrica de esta escala, ... por lo que el valor de conjunto es primordial para no perder el sentido de patrimonio industrial"70.

Al igual que en Schwager, se han logrado restaurar las viviendas industriales, a través de algunos proyectos gubernamentales, como el "Quiero mi barrio" o la incorporación en los planes reguladores de la comuna, que declara un polígono como zona de conservación histórica, posibilitando el que se invirtieran recursos para la restauración de viviendas. También los daños provocados por el terremoto del año 2010, posibilitaron contar con recursos para la reconstrucción patrimonial de viviendas de los sectores más antiguos. Sin embargo, tampoco existe una política muy clara de restauración de espacios

\footnotetext{
${ }^{70}$ Consejo de Monumentos Nacionales. Decreto 0166 - 31.07.2017. Declara Monumento Nacional en categoría de Monumento Histórico a la "Fábrica Textil Bellavista Oveja Tomé", ubicada en la comuna de Tomé, Provincia de Concepción, Región del Bío-Bío. www.monumentos.cl
} 
públicos. Hay algunos edificios que están aún en muy buenas condiciones, pero hasta este momento no hay claridad si el gobierno municipal, regional o nacional destinarán recursos para su restauración para darle nuevos usos por parte de la comunidad, como sucede con el edificio del Deportivo y Cine Bellavista-Tomé, declarado Monumento Histórico por el Consejo de Monumentos Nacionales a través del Decreto 46 de 23 de enero de 2013, pero que hasta la fecha, a pesar de ser de propiedad del Municipio, no se restaura.

En síntesis, estos dos territorios constituyen ejemplos emblemáticos de resistencia al olvido. Desde sus comunidades organizadas han logrado mantener viva su memoria, transformando el despojo de su cultura industrial, en un patrimonio vivo.

\section{Bibliografía}

\section{Fuentes Impresas}

Enrique Aliste, Miguel Almuna, Alonso Contreras y Valeria Sandoval. "Industrialización, Desarrollo y Ciudad: Transformaciones Socio-demográficas y Espaciales en la Geografía Social del Gran Concepción (1950-2010)", Revista Invi, Instituto de la Vivienda/Facultad de Arquitectura y Urbanismo/ Universidad de Chile, Vol. $27 \mathrm{~N}^{\circ} 75$, agosto 2012, pp. 21-71.

Rolando Álvarez, "El Plan Laboral y la negociación colectiva: ¿Origen de un nuevo sindicalismo en Chile? 1979-1985", Boletín del Instituto de Historia Argentina y Americana "Dr. Emilio Ravignani”, Tercera serie, núm. 35/36, segundo semestre 2011 / primer semestre 2012, pp. 92 115.

Jorge Ayala. Historia del movimiento sindical de Huachipato 1970-2013. Procesos de articulación y acción política. Editorial Escaparate, Concepción-Chile, 2016.

Eduardo Becker, Sebastián Pérez, Maura Saavedra y Eduardo Saldías, Bellavista. Memoria Oral de un pueblo industrial, Consejo Nacional de la Cultura y las Artes, Fondart Creando Chile, Concepción, Chile, 2010.

Francisco Campo, Antecedentes del neoliberalismo en Chile (1955-1975), Santiago, Universidad de Chile, 2013.

Armando Cartes, “Fábrica de Paños Bellavista, Espacio y Tiempo (1865-1970)”, en Armando Cartes, Rodrigo Luppi, Luis López, Bellavista Oveja Tomé. Una fábrica en el tiempo, Ediciones Universidad San Sebastián, Universidad San Sebastián, Concepción, Chile, 2012, pp. 23-48.

Compañía de Acero del Pacífico. Desarrollo y Expansión de Huachipato. Preparado por el Servicio de Divulgación Industrial de la Compañía de Acero del Pacífico S. A., Santiago, Litografía Stanley, 1962.

Sofía Correa, María Consuelo Figueroa, Alfredo Jocelyn-Holt, Claudio Rolle, Manuel Vicuña, Historia de Chile en el siglo XX: balance paradojal, Santiago, Editorial Sudamericana, 2001. 
Carlos De Mattos, "Modernización neocapitalista, reestructuración productiva y territorial en Chile, 1973-90”, Revista Eure, Vol. XVIII, N 54, 1992, pp. 15-30.

Diario El Sur, Concepción. Años 1970-1972-1973

María Díaz Castillo, Labor del Servicio Social en las Compañías Carboníferas de Lota y Schwager en el año 1961, Memoria de Prueba para optar al título de Asistente Social, Universidad de Concepción, Chile, 1962.

Enrique Fernández, Estado y sociedad en Chile 1891-1931: el Estado excluyente, la lógica estatal oligárquica y la formación de la sociedad, Santiago, Ediciones LOM, 2003.

Ricardo Ffrench-Davis, Entre el neoliberalismo y el crecimiento con equidad: tres décadas de política económica en Chile. Santiago, Chile: JC Sáez, 2003.

Pablo Fuentes, "Del familisterio al condensador social. El colectivo Chollín como arquetipo moderno". Revista AUS 17, pp. 49-55

Rodrigo Ganter, Alejandra Brito, "Cartografías de lo cotidiano: usos, relatos y disposiciones del espacio en el contexto de la industria minera y textil del Gran Concepción (1940-1973)". Revista Austral de Ciencias Sociales No:33 (en prensa).

Manuel Antonio Garretón, Neoliberalismo corregido y progresismo limitado: los gobiernos de la concertación en Chile, Santiago, CLACSO, 2013.

Maurice Halbwachs: La memoria colectiva, Prensas Universitarias de Zaragoza, Zaragoza, España, 2004.

Karla Lagos, "Evolución urbana del barrio industrial Bellavista", Seminario de Título, Carrera de Arquitectura, Universidad de Concepción, 2009.

Mariela Lavoz y Silvia Shejade, La experiencia de un proceso. Percepciones de los hombres y mujeres de Coronel acerca de la reconversión laboral y productiva. Seminario de Título, carrera de Pedagogía en Historia y Geografía. Universidad de Concepción, 2010.

Rodrigo Luppi San Martín, “Con el alma en un hilo. Los difíciles años: 1970-2011”, en Armando Cartes, Rodrigo Luppi, Luis López, Bellavista Oveja Tomé. Una fábrica en el tiempo, Ediciones Universidad San Sebastián, Universidad San Sebastián, Concepción, Chile, 2012, pp. 51-65.

Patricio Meller, Un siglo de economía política chilena (1890-1990), Santiago, Editorial Andrés Bello, 1996.

Oscar Muñoz, "Algunas Reflexiones Sobre la Política de Reconversión en la Industria del Carbón”, Colección de estudios CIEPLAN N 41. Diciembre de 1995. CIEPLAN, Santiago.

Aníbal Navarrete, Gina Inostroza, Tres tesis sobre Tomé: Tres enfoques sobre la historia textil de Tomé. Editorial: Al Aire Libro, Tomé, 2009. 
Leonel Pérez, "El barrio Puchoco en Schwager. Cuando la industria construye el paisaje cultural", en Urbano, Vol. $\mathrm{N}^{\circ} 11, \mathrm{~N}^{\circ} 16,2008$, pp. 47-58.

Programa de Recuperación de Barrios, Historia del Barrio Puchoco-Schwager Coronel. Mi barrio, una historia para compartir. Ministerio de Vivienda y Urbanismo, Secretaría regional Ministerial del Bío-Bío, Concepción, 2011.

Gabriel Salazar, Julio Pinto, Historia Contemporánea de Chile. La economía: mercado, empresarios y trabajadores, Santiago, LOM, 2002.

Magdalena Saldaña, "Coser y ¿Cantar? La quiebra de 2007 en la voz de los trabajadores”, en Armando Cartes, Rodrigo Luppi, Luis López, Bellavista Oveja Tomé. Una fábrica en el tiempo, Ediciones Universidad San Sebastián, Universidad San Sebastián, Concepción, Chile, 2012, pp. 113-130.

José Sierra Álvarez, El obrero soñado. Ensayo sobre el paternalismo industrial (Asturias, 18601917), Siglo XXI, Madrid, España, 1990.

Pilar Vergara, Auge y caída del neoliberalismo en Chile, Santiago, FLACSO, 1985.

Steve Stern, "De la memoria suelta a la memoria emblemática: hacia un recordar y el olvidar como proceso histórico (Chile 1973 - 1998)". En M. Garcés y otros Memoria para un nuevo siglo. Chile, miradas a la segunda mitad del siglo XX. LOM Ediciones, Santiago de Chile, 2000, pp. 11-33

Carlos Vignolo, "De la desindustrialización a una nueva industrialización en un Chile democrático", CED, Centro de Estudios del Desarrollo, Santiago, Chile, 1986, pp. 204-205.

\section{Fuentes Digitales}

Macario Alemany García, El concepto y la justificación del paternalismo. Tesis para optar al grado de Doctor en Derecho por la Facultad de Derecho de la Universidad de Alicante, 2005. http://www.archivochile.com/tesis/13_otros/13otros0013.pdf.

Decreto 1262 de 18 de noviembre de 1953, www.leychile.cl

Consejo de Monumentos Nacionales. Decreto 220 - 31.05.2010. Declara Zona Típica o Pintoresca el sector Puchoco-Schwager ubicado en la comuna de Coronel, Provincia Concepción, de la VIII Región del Bío-Bío. www.monumentos.cl

Consejo de Monumentos Nacionales. Decreto 0166 - 31.07.2017. Declara Monumento Nacional en categoría de Monumento Histórico a la "Fábrica Textil Bellavista Oveja Tomé", ubicada en la comuna de Tomé, Provincia de Concepción, Región del Bío-Bío. www.monumentos.cl

David Harvey, Breve historia del neoliberalismo. En https://teoriaeconomicatercersemestreri.files.wordpress.com/2012/09/breve-historia-delneoliberalismo-de-david-harvey1.pdf 
Griselda Lemiez, Relaciones laborales paternalistas en la industria del cemento. El caso de Avellaneda, Olavarría 1935 - 1973, en http://www.eumed.net/libros-gratis/2013a/1288/index.htm.

\section{Fuentes no impresas}

Alejandra Brito, Rodrigo Ganter, Marcos Muñoz. Informe Final: "Estudio sobre la transformación Socio-cultural en la comuna de Coronel”. Departamento de Sociología, Universidad de Concepción, 2009. MIMEO.

Talleres de Mapeo Colectivo en barrio Bellavista, Tomé.

Talleres de Mapeo Colectivo en barrio Puchoco-Schwager, Coronel.

Relatos de vida ex trabajadores/as de la Fábrica Bellavista, Tomé

Relatos de vida ex trabajadores de la Carbonífera Schwager, Coronel. 